\title{
Trainee Teachers' Collaborative and Reflective Practicum in Kindergarten Classrooms in Greece: A Case Study Approach
}

\section{Efthymia Gourgiotou}

Pedagogical Department of Preschool Education, University of Crete, Greece

\begin{abstract}
How to cite this paper: Gourgiotou, E. (2017). Trainee Teachers' Collaborative and Reflective Practicum in Kindergarten Classrooms in Greece: A Case Study Approach. The Educational Review, USA, 2(1), 117-128. http://dx.doi.org/10.26855/er.2018.01.001
\end{abstract}

Corresponding author: Gourgiotou Efthymia, Ph.D., Assistant Professor, Pedagogical Department of Preschool Education, University of Crete, Greece.

\begin{abstract}
This chapter examines the reform outcome of reflective teaching introduced by the Department of Preschool Education among the teacher trainees in University of Crete, during their practicum. The main purpose of this action research project was to identify principles and specific strategies to the development of collaborative work employed from the participants to support and enhance the development and learning of young children. The participants of the study (70 teacher trainees, and the University Kindergarten Mentor, were trained all together twice in the beginning of each semester, by Course Supervisor) on a adapted and modified model of 'Collaborative Learning Training', focused to help teacher trainees on: a) the planning and teaching, b) the intervention on the learning environment of kindergarten, $c$ ) the formative evaluation of children, and d) the change of teaching practices, using curriculum differentiation to respond to children's diversity. Data collection from interviews, surveys, observations and teacher trainees' portfolios showed the engagement of all the participants in a democratic, critical reflection and creative problem-solving procedure with favorable predictions for collaborative teaching and learning in future professional settings.
\end{abstract}

\section{Keywords}

Trainee Teachers, Collaborative and Reflective Practicum, Kindergarten

\section{Introduction}

Most teacher education institutes around the world prepare their trainee teachers (hereafter, simply, 'trainees') for teaching in the real classroom contexts through 'the practicum' that is a teacher education course unit consisting of both theoretical and practical aspects. Barry and King note that, "teaching practice [practicum] provides the opportunity to apply the principles of teaching and learning that have been studied during course work" (Barry and King, 2002: 35) and to integrate educational theory and practice. Research studies in the United Kingdom, USA, Canada and Australia, suggest that trainees view their practicum experiences as extremely important and essential (Ong'ondo, and Jwan, 2009; Zeichner, 1990). They value the practicum as an opportunity to develop a professional identity, and to teach and participate in multiple, complex and concrete experiences essential for meaningful learning and teaching (Brock and Grady, 1998; Huling-Austin, 1992). They further believe that the practical experiences of expert teachers (i.e. mentors) who observe their lessons, receiving mentor feedback and practicing various teaching strategies during the school experience (i.e. the practicum) are the most important factors in trainees' professional growth. For many, the practicum is the time to 
reflect whether or not teaching is the career for them (Barry and King, 2002). From this perspective, the practicum has the power to critically shape the trainee's perception of teaching and children's learning (Gustason and Rowell, 1995 as cited in Grootenboer, 2006).

Consequently, there is a general agreement by both trainees and their educators that the practicum is one of the most useful, if not the cornerstone component of teacher education programmes (Barry and King, 2002; Cameron and Wilson, 1993). Whilst in the past, trainee learning has been considered to be an individual affair, more recently it has become clear that learning through collaboration may be better facilitated, as well as enhancing professional relationships amongst trainees (Liberman and Pointer Mace, 2008). Importantly, for early childhood education, collaboration and partnership are well established within epistemology, scholarship and policy in early childhood education. Interpersonal and group skills (McLean, 1991; Walsh, and Elmslie, 2005)-what Goodfellow (1995:14) refers to as "groupness" are deemed as essential features of early childhood education environments.

Within this context of early childhood education, the role of the trainees has changed towards the expectation that they work with their peers and mentors in more collegial ways. This change to a shared focus rather than an individual focus is significant because it represents a commitment to reciprocal learning relationships and a deepening participatory process (Le Cornu and Ewing, 2008). Moreover, trainees need to be able to use their minds, feelings and reasoning abilities to critically reflect upon their classroom practices and the quality of children's learning. As indicated by Hoover (1994), they should be more than just technicians who carry out prescribed instructional strategies and content. Furthermore, reflecting and writing about teaching enables trainees to document and learn from their peer teaching experiences and in doing so assist them to overcome issues relating to their classroom experiences.

Two main forms of collaboration are identified in the literature as being very valuable during the practicum -that amongst trainees (i.e. peers) and between trainees and their mentors in the placement schools. Research on peer support is rather minimal compared to other aspects of the practicum. One aspect of this research that has previously been undertaken is the advantage of paired trainee placements during the practicum (e.g. Hsu, 2005; Nokes et al., 2008; Numrich, 1996). Studies found out that paired placements enhanced trainees' learning opportunities during the practicum especially through discussions on shared teaching and observations of each other. Another aspect of collaboration among trainees reported in recent research is on peer teaching. Wilson and I'Anson (2006) conducted a study in the UK, which evaluated the success of a model of teaching practice "which uses micro teaching as a preparation for school experience" (p. 356). More recently in the UK, Britton and Anderson (2010) conducted a study in which trainees collaborated during a practicum in a training model called 'peer coaching'. Their findings concluded that the trainees were able to learn both the principles and the practice of peer coaching with ease and that peer coaching enabled them to develop a deeper understanding of pedagogy. This in turn improved their classroom practice considerably over the practicum semester. Consequently, Britton and Anderson (Ibid. p.7) recommended "the addition of peer coaching as a requirement in the pre-service teacher training process".

Further research literature, indicates that peer placements tend to facilitate a richer learning context than individual placements (Turney, Eltis, Towler, and Wright, 1985). Trainees, also, tend to seek more support from peers (Beck, and Kosnik, 2002), than mentors and supervisors. Contrastingly, some trainees do not want team teaching arrangements as it denies them the "real experience" of solo teaching" which they would be involved in after qualification. Others studies, have indicated that collaboration in the form of peer coaching is effective in addressing isolation (Little, 1982) as well as helping teachers to apply new skills and strategies in their classroom (Joyces et al., 1992; Reiman and Johnson, 2003). Additionally, various researchers have shown that peer coaching can promote collegiality and professionalism (Neubert and Binko, 1992; Wynn and Kromrey, 1999) and reflection amongst trainees (Vidmar, 2006; Wynn and 
Kromrey, 1999) and most importantly ensuring continuity in children's learning and development (Kwo, 2001).

However, the above researchers cautioned that any implementation of peer coaching and peer placement models needs to be done with care, especially as it requires considerable time to train the trainees and supervisors, and an extended practicum. Implementation of such a model, in practicum sessions in developing countries would therefore need to take into consideration the high number of trainees, and the resources, among other factors (European Trade Union Committee for Education, 2008).

\subsection{Implementing a New Model of Collaborative Training: A Case Study Approach}

\subsubsection{The Greek Context}

This study concerns the implementation of a new model of trainees' practicum based on learning through collaboration. In the Early Childhood Department at Crete University in Rethymno, Greece, the practicum in the 4-years Teacher Education Programme has three levels. Each level involves two sessions of school experiences across the first and second semester. This means that trainees will undertake one day of kindergarten classroom observation every week during the second year of the programme ( Level I), one day solo teaching per week for eight weeks during the third year ( Level II), and four weeks of 4 days per week of solo teaching during the fourth year ( Level III).

Given the number of trainees on the programme, which tends to be around 70, there is an insufficient number of cooperative kindergartens available to provide placements for trainees in Rethymno. This means, the university is obliged to allocate a group of four trainees to a kindergarten classroom that requires each of them to undertake solo teaching, on different themes, according to the technical framework of the department's practicum. Consequently, this action led to concerns in that it affected the continuity of children's learning, particularly when the trainees are obliged to follow the project-based teaching approach of the training programme. Therefore, to ensure continuity in the process of trainees' learning to teach throughout the practicum, consideration was given to how trainees can provide valuable mutual support to one another. This dimension of peer support can be regarded as a strategic resource for the teaching practicum, in addition to the support from university mentors and university course supervisors.

Moreover, as a further set of challenges, there is no formal training for mentors (university teachers) to assist trainees in terms of: understanding the roles of mentors and mentees; providing practical teaching knowledge; sharing methods and materials; observation, planning and organising lessons; affective support and reflective teaching in the teaching practicum.

\subsection{Focus of Research}

The main aims of the case study were to:

a. Examine trainees' reflective teaching practice in the context of kindergarten teacher education whilst working in pairs within groups of four in kindergarten classrooms. In doing so, we set out to explore how these trainees, experienced reflective practice whilst placed in a classroom with three others peers. We were interested in finding which collaborative strategies were identified as being most conducive to the development of an effective professional relationship between trainees.

b. Investigate the advantages and disadvantages of implementing this collaborative, training model and to identify specific strategies employed by the trainees to support the continuity of young children's development and learning.

As a goal of the study it is hypothesized that the collaborative, training model will lead to an improvement in the quality of trainees' learning, as well as maintaining a continuum in the quality of children's learning and in doing so lead to an enhancement in the quality of teacher education and training offered by the university. 


\section{Methodology, Data Collection and Analysis}

The study was pursued using qualitative research method in order to get an in-depth view of the issues. Furthermore, this study adhered to the following characteristics of qualitative research (Glesne, 2006; Paton, 2002):

a) focus on explorative and descriptive

b) non-emergent design

c) purposive sampling

d) data collection in a natural social setting

e) focus on human-as-instrument.

Trustworthiness in triangulation of data (Glesne, 2006; Lincoln and Guba, 1985; Paton, 2002;) was ensured by involving four data collection components: a) semi-structured interviews, b)surveys, using short answers and rating scales, c) non-participant observation and d) document review (trainees' portfolio's assessment). The trainee's portfolio consisted of: the artefacts included in the trainees' lesson planning; journal of teaching implementation (logs), written reflections on the overall experience; self-evaluation; children's assessment and observation reports, record keeping, photos, etc.). The inductive approach of grounded theory analysis (Glaser and Strauss, 1967) and deductive coding were used to analyse the data of trainees' self-assessments, written reflections and logs all included in their portfolios. The constant comparative method generated both the focus categories and the reflective categories. The journal entries were coded for Van Manen's (1977) levels of reflectivity to determine the reflection levels of the teacher trainees according to: a) Technical Rationality, b) Practical Action, and c) Critical Reflection.

\subsection{Ethical Considerations}

Relevant ethical issues such as confidentiality, anonymity and permission to withdraw from the study were fully considered during the process of data collection, analysis and interpretation (Cohen et al., 2007). In order to get close to trainees' experiences and to understand personally the details of their actual experience, the researchers had a close relationship with the participants within the context of the study (Patton, 2002). Despite the nature of the researcher involvement, the trainees voluntarily participated in the study as an opportunity to share their experiences. In exercising autonomy trainees had the opportunity to choose a suitable time and date for the interviews. In relation to voluntary participation, participants were given a written informed consent form before starting each interview. They had time to read it and ask anything related to the study before they gave their consent to engage in the interviews. The purpose of the written informed consent was to inform the trainees about the research, and their right to withdraw if they wished. Finally, in relation to the portfolio's construction, the trainees were asked to keep this as a record of their practicum experiences and to submit it during the final week of their practicum.

\subsection{Participants}

A cohort of 70 fourth-years early childhood trainees participated in the study. In completing their practicum trainees were paired within groups of 4 trainees whilst on practicum. In pairing trainees this was done on a free choice basis and groups of 4 trainees were allocated to 18 kindergarten classrooms (however, one classroom received only a pair of trainees).

\subsection{Collaborative Learning Training Model}

The participants in this study received training as a cohort on collaborative working. This modified 'Collaborative Learning' training model focused to help trainees to develop a continuum of teaching practice as a tool for self-reflection, 
goal setting, and inquiry into practice through different techniques such as exposition, discussion, demonstrations, guided discovery, and open inquiry. This continuum of teaching practice provided a common language about teaching and learning of the trainees' on:

a) the planning and teaching of a theme in the kindergarten;

b) the intervention of the learning environment of kindergarten classroom;

c) the formative evaluation of children;

d) the change of teaching practices, using curriculum differentiation to respond to children's diversity, and, also, included background to teamwork and working with peers, and tutorials designed for trainees to get to know each other.

\section{Findings}

This collaborative working programme appeared to be effective for the following reasons:

a. The peer support: this was highly valued by the trainees and seen as an important aspect of their practicum experience.

b. The continuity of children's learning: this emerged from the portfolio's content analysis, and

c. The creation of a community of learners: this was confirmed by all participants.

\subsection{The Peer Support}

Based on rating scales transcripts we have conclude that trainees, before the beginning of the project, understand peer support as communication $(100 \%, \mathrm{n}=70)$, co-operation $(100 \%, \mathrm{n}=70)$, listening $(38,58 \%, \mathrm{n}=27)$, constructive criticism $(71,42 \%, \mathrm{n}=59)$, compromise $(15,71 \%, \mathrm{n}=11)$, organization $(88,57 \%, \mathrm{n}=62)$ and accepting help and ideas $(70 \%, \mathrm{n}=49)$ between them. After the project advantages of working in pairs were listed as: moral support $(94,29 \%, \mathrm{n}=66)$, able to share ideas, thoughts and feelings $(95,71 \%, n=67)$, share the workload $(67,14 \%, n=47)$, learn from one other $(90 \%$, $\mathrm{n}=63)$, and get feedback $(75,1 \%, \mathrm{n}=53)$. It is shown in the Table 1 .

Table 1. Trainees' perception of the term 'peer support' based on rating scales transcripts pre intervention and post intervention.

\begin{tabular}{lcrlcc}
\hline \multicolumn{2}{c}{ Before the project } & \multicolumn{3}{c}{ After the project } \\
\hline \multicolumn{1}{c}{ Peer support understanding } & $\%$ & $\mathrm{n}$ & & Peer support understanding & $\%$ \\
& $100 \%$ & 70 & share ideas, thoughts and feelings & $95,71 \%$, & 67 \\
communication & $100 \%$, & 70 & moral support & $94,29 \%$, & 66 \\
co-operation & $38,58 \%$, & 27 & learn from one other & $90 \%$, & 63 \\
listening & $71,42 \%$, & 59 & get feedback & $75,1 \%$, & 53 \\
constructive criticism & $15,71 \%$, & 11 & share the workload & $67,14 \%$ & 47 \\
compromise & $88,57 \%$, & 62 & & \\
organization & $70 \%$ & 49 & & \\
accepting help and ideas & & & & \\
\hline
\end{tabular}

On the other hand, trainees reported some difficulties working in peer groups as: 'finding time for collaboration' (12, $85 \%, n=9)$; 'a lot of work (specially for the construction of portfolio)' $(32,85 \%, n=23)$; 'personal differences such as the teaching style of the trainees and the economical level' $(8,57 \%, \mathrm{n}=6)$; 'conflicting ideas' $(7,14 \%, \mathrm{n}=5)$; and 'being compared to another' $(4,28 \%, n=3)$.

Trainees' comments interview transcripts help to pin-point the fine-grained issues which cause problems for trainees during pairing. The issues identified are best exemplified by the following excerpts:

"We needed more time to get to know our pairs before teaching, and more time to construct our portfolio, as we had little of time to reflect on these writings". (Trainee 43) 
"We needed similar levels of commitment, enthusiasm and passion for teaching... willingness to share ideas and contribute fairly". (Trainee 68)

"I like to have the support of my colleagues but I need to be better on my own to learn to stand on my own feet in the classroom, because in future I will be alone in my classroom". (Trainee 21)

Trainees frequently noted that competition and comparison between students was challenging. But not all trainees viewed this as negative. For example:

"Although I got on well with my group, it would have been better if I had chosen who I wanted to be paired with. One problem was that they were a lot more confident than me and I didn't seem to be listened to as much. I also felt the University teacher may compare us and feel I wasn't as good. However, this did have an advantage of forcing me to work better". (Trainee 1)

The most effective collaborative strategies used by trainees during the practicum were: the common interventions, and conversations $(98,57 \%, n=69)$; followed by the frequent meetings $(95,71 \%, n=67)$, the searching of instructional materials resource $(94,28 \%, \mathrm{n}=66)$; the reflective portfolio with shared observations $(87,1 \%, \mathrm{n}=61)$, the development of critical friendships $(77,1 \%, \mathrm{n}=54)$, the team planning $(68,57 \%, \mathrm{n}=48)$, and the teaching and modelling $(55,71 \%, \mathrm{n}=39)$.

\subsection{The Continuity of Children's Learning}

The findings on the focus of the trainees' reflection (form portfolios data) concurred with previous studies (Loughran, 1996; Subramanian, 1997) which found that trainees have been writing about issues related to their course and various concerns. Those concerns included themselves as well as classroom teaching and learning. The current study has categorised the focus of the teacher trainees' reflections into self, children, teaching, school, supervision, learning and preparation.

Further categorisation of the reflective entries in trainees' portfolios revealed that trainees were capable of describing and analysing personal feelings, concerns, situations, experiences and problems. These findings were in close agreement with other studies (Surbeck et al., 1991). The trainees were also able to suggest ways on how to change or improve their personal characteristics, their teaching methods or activities and children's behaviours or attitudes. They demonstrated abilities to analyse situations and experiences as revealed by Surbeck and colleagues (Ibid.) as the 'comparative elaboration' sub-category.

When categorising for levels of reflectivity, the study also revealed that trainees operated at the first, "technical competency' level, at the second, 'analysis of teaching decision' level and at the third, 'critical reflection' level. Trainees showed the ability to use suitable teaching methods or techniques to achieve teaching and learning objectives. They managed to develop and describe their own assumptions and beliefs; to analyse and make judgements about the choices that they made in their teaching efforts and they were identified as capable of taking into consideration moral and ethical outcomes of their teaching action. The consequences of their teaching actions in respect to children's needs, justice and equality were, also, thought through by the trainees.

Portfolio's content analysis showed that the majority of trainees succeeded to improve the coherency and continuity of the curriculum, the ability to plan and teach using an uninterrupted flow of ideas and /or information, and in doing so ensured continuity in children's learning. Learning experiences and activities for young children were systematic and showed a logical connection and consistency. Diverse elements, relationships, and values were all integrated.

More specifically, in planning a theme, continuity was achieved through (Table 2):

a) setting aims and learning outcomes or objectives $(85,7 \%, \mathrm{n}=60)$;

b) thinking about the structure of the session and timing of activities $(98,57 \%, \mathrm{n}=69)$; 
c) taking decision on the best teaching and learning methods to achieve the learning outcome $(91,4 \%, \mathrm{n}=64)$;

d) listing content and key subthemes, and undertaking more research if needed (90\%, $n=63)$;

e) improvement in the lesson plan $(75,71 \%, \mathrm{n}=53)$;

f) identification of the learning resources and support material $(92,85 \%, \mathrm{n}=65)$ and

g) finalisation of any linked assessment or evaluation $(97,1 \%, n=68)$.

Table 2. Trainees' continuity improvement according portfolio's content analysis.

\begin{tabular}{lc}
\hline Continuity in planning a theme & $\%, \mathrm{n}$ \\
\hline a) setting aims and learning outcomes or objectives & $85,7(60)$ \\
b) thinking about the structure of the session and timing of & $98,57(69)$ \\
activities & \\
c) taking decision on the best teaching and learning methods & $91,4(64)$ \\
to achieve the learning outcome & \\
d) listing content and key subthemes, and undertaking more & $90(63)$ \\
research if needed & \\
e) improvement in the lesson plan & $75,71(53)$ \\
f) identification of the learning resources and support material & $92,85(65)$ \\
g) finalisation of any linked assessment or evaluation & $97,1(68)$ \\
\hline
\end{tabular}

Trainees' talk (as monitored via self-assessment content analysis included in portfolios) about tasks and ideas from the past and in the future played an important part in making connections between ideas, tasks, and lessons. The trainees' speech organised, foreshadowed, summarised, and connected classroom tasks, ideas, and practices to help their children in "keeping track of the multi-layered nature of classroom activity and work" (Leinhardt and Steele, 2005: 92). This linking or connecting talk also played an important role in shaping the direction and pace of children's learning-focused interactions.

Based on the philosophical foundations of "Project Approach" work reside in Progressive education, and in particular in the work of Dewey (1938), trainees planned a theme (and not a topic) with the intension to connect everyday home and school experiences of children leading to an ever-widening and reflective understanding of the new teaching concept.

At the level of classroom organization and management, trainees provided a caring classroom community that emphasized strong interpersonal relationships with their young children to form a functional and cohesive environment for all learners. Using this model, trainees displayed a helpful nature, showed respect for all children's well-being, offered help with class work, and encouraged a cooperative classroom community, thus minimizing potential misbehaviour issues. Key strategies concurred with findings of previous studies (Simonsen et al., 2008), for developing a successful management plan, such as:

1. Space: remain cognizant of classroom design and arrangement as a way to reduce potential disruptions ( $97 \%$ in agreement);

2. Structure: provide students with a structured classroom environment to ensure a better level of engagement, which concurrently fosters stronger peer communication (79\% in agreement);

3. Continuity of response: present consistent systems and practices to monitor and respond to acceptable and unacceptable behaviours and choices (63\% in agreement).

Observation notes by the lesson supervisor documented that trainees considered not only ways to diminish misconduct, but emphasized a strong trainee-child relationship as one of the most important factors to create and foster a caring classroom, responding to all children needs. These practices reflected the strategy proposed by many specialists in classroom management (Nie and Lau, 2009). Trainees also viewed themselves as facilitators and mentors who inspire creativity, encourage academic inquiry, and motivate learning among their students. This practice helped them to establish a 
well-structured and inclusive environment, and to promote and cultivate positive classroom leadership and reduce misbehaviours (Stein, 2010).

In the construction and management of supportive materials trainees used a repertoire of sources for the single lesson plan that included: the resources produced by individual trainees themselves, the Web, the interpersonal resources, the libraries, the observation and the museum exhibitions. The information sources used for the lesson plan were of a broad scope comprising both documentary and interpersonal sources, various media and content such as fiction, personal and educational. The importance here is that trainees shared all the supportive materials and very often left it in classroom for the next trainee's teaching. In many cases they were obliged to construct all supportive materials together, such as puppetry, short videos, PowerPoint slides, cards, etc.

Concerning the teaching approach, la majority of the trainees applied the project curriculum (Table 2) mean score were $\mathrm{m}=5.1325, \quad \mathrm{SD}=.71551$, as compared to thematic approach (Table 3) where $\mathrm{m}=2.0219$ and $\mathrm{SD}=.83653$ and classical approach where $\mathrm{m}=2.8316$ and $\mathrm{SD}=.87201$. They used project approach as a continuous spiral, relying on current activities as a 'moving force' toward new and more rigorous inquiries and interests, according to Dewey's theory (1938) about continuity and experience (McAninch, 2000). Trainees started with a heartfelt desire on the part of the children and included the processes of observation, information gathering, analysis, and synthesis in the information of the plan of action toward the goal, which itself was open to revision. They integrated content from both the scientific and the social knowledge areas with this content being taught in learning experiences in such a way that the subject matter or concept was made meaningful for children. They focused instruction at the appropriate level of difficulty for children considering previous learning and activities that followed. The instruction was sensitive to how children learned and developed, and included learning experiences that supported their intellectual and social development. They further united the learning theory and teaching strategies in the activities and created a positive learning environment with high expectations and high standards for all children.

Table 3. Teaching approaches used by trainee teachers.

\begin{tabular}{lcc}
\hline Teaching Approaches & Mean & Std deviation \\
\hline Project approach & 5.0380 & 0.67043 \\
Thematic approach & 2.0219 & 0.83653 \\
Teacher-led approach & 2.8316 & 0.87201 \\
\hline Mean indicators 1-2.99= low; 3.00-4.99= moderate; $5.00-7.00=$ high &
\end{tabular}

In the case of children with learning difficulties as for the linguistically and culturally diverse children, trainees used the 'Classroom Support Plan', made it by the course supervisor, incorporating the simple, informal problem-solving approaches to support their needs. The 'Classroom Support Plan', as a continuum of support, focused on identifying and addressing the special educational needs of individual children who required approaches to learning and/or behaviour within the classroom which are additional to or different from those required by other pupils. This intensive teaching support included more focused circle time or small group activities or individual interventions. The support also included the adaptation of learning environment and/or further differentiation of the curriculum, monitoring of children's response over time, engagement of the children and finally, a simple written record of what has been done. Concerning observation and assessment of children, all the trainees developed ways to plan, interact, monitor, document, assess and reflect about children's progress. More specifically, they monitored the children's learning day-to-day, by observing the children as they engaged in play, in circle time and during their work in small groups, and selectively documented their learning. The majority of them $(43,4 \%, n=62)$ interpreted the documented evidence of children's learning with their group peers and together made judgements for decisions that informed the next 
trainee's teaching. This meant that the next trainee considered the decision-making judgements and integrated them in his/her planning. When the first circle of teaching was complete, all trainees reviewed the information collected about children's progress and made judgments about the level and the kind of support intervention that children needed on an individual basis. The judgements they made informed their moment-by-moment and day-to-day decisions about the learning environment, ways to work most effectively with peer groups, and interactions with children to promote learning.

This enabled them to be responsive to children, along a continuum, to build connections between children's prior, current and future learning experiences in order to promote continuity of learning, as reported elsewhere (Gourgiotou, 2014). The following gives an insight into the trainees' experiences:

"I was able to compare / share understandings of children, observations and planning and see the different techniques and strategies of my partners". (Trainee 55)

"It gave me the opportunity to change ideas off each other and to share experiences such as group times. We were able to discuss situations or behaviours and come up with a solution together without having to get the classroom teacher involved". (Trainee 31)

\subsection{A Community of Learners}

The perceived benefits of peer placements and collaborative work for trainees through the "Collaborative Learning Training Model" included:

- the development of strong personal friendships;

- $\quad$ a safe, respectful, less stressful and productive learning for trainees;

- the sharing of responsibility,

- the acquisition of creative problem solving abilities, and

- the enhancing links with the local community, because the trainees were so happy and proud of their work that they wanted to show to other people. As such, an exhibition was organized in the center of the town, voluntarily, without funds and proved to be a great success.

Whilst all trainees acknowledged the benefits of being placed with other trainees on school placement, the collaborative training model did seem to place increased demands on the trainees' interpersonal, reflection and dialogue skills. Forming a professional community requires teachers to engage in both intellectual and social "deep work" - new ways of thinking and reasoning collectively as well as new forms of interacting interpersonally (Grossman et al., 2001). It, also, requires trainees to:

a) live with discomfort and tension as they move from safe, comfortable and predictable situations to ones involving risk-taking and uncertainty;

b) embrace these more tentative practices and feelings,

c) helping others who were similarly experiencing some dissonance, and

d) cope with the challenge of interpersonal and epistemological differences which surfaced throughout the process. This is a very different position indeed to the passive role adopted in the traditional practicum and different too from the more active, but individualistic role often adopted in the reflective practicum (Freese, 2005).

We would argue that the role of trainee in the learning communities' model requires much 'emotional labour' as stated by Hargreaves (1998). Hargreaves (Ibid.) uses this concept to describe the work that teachers do when they consciously work themselves up into a state of actually experiencing the necessary feelings that are required to perform one's job well. 
Unfortunately, three groups of trainees' had a negative practicum experience, because collaboration between them and classroom teachers was not well structured, a feature which is also reported by previous studies (Graham, 2006).

"I was committed but we had a communication breakdown. She obviously had very different expectations to how I interpreted everything I learnt" (Trainee 22).

According to the university kindergarten teacher, for most trainees, their initial worries about their classroom teacher dissipated once on practicum. However, the overriding pressure to pass the practicum often influenced what and how they learnt. When their pedagogical beliefs and practices did not concur with those of their classroom teacher, they reported that the best approach to establishing a working relationship was to conform rather than 'rock the boat'.

\section{Conclusions}

The findings from this project have strengthened our conviction that collaborative working on practicum produces overall engagement in a democratic, critical manner and a creative problem-solving procedure, which will help them to plan and organize future collaborative teaching and learning projects whether in schools or other organizations.

Teamwork is recognised as an important component of the teaching profession and skills related to building efficient teams and leadership qualities need to take a higher profile in early childhood teacher education programs.

There was evidence of scaffolding, as trainees reported sharing, supporting and helping one another to find solutions and alternatives to dilemmas and concerns. The planning component of this practicum was a significant step forward for trainees in terms of depth of preparation and documentation. The strategies of keeping a portfolio were intended to provide opportunities for reflection on action and to further stimulate the professional dialogue between them.

The study also revealed that trainees can reflect at the first, 'technical competency' level, at the second, 'analysis of teaching decision' level, and at the third, 'critical reflection' level. They showed the ability to use suitable teaching methods or techniques to achieve teaching and learning objectives. They managed to develop and describe their own assumptions and beliefs and to analyse and make judgements about the choices that they made in their teaching efforts. They were identified as capable of taking into consideration moral and ethical outcomes of their teaching action. The consequences of their teaching actions in respect to children's needs, justice and equality were thought through by the trainees.

Evidence, also from the study confirms the great influence of the university mentor on trainee's peer working and learning.

Finally, it has been demonstrated in this study that the role of the 'trainee' in a Collaborative Learning Training Model of practicum, with its commitment to reciprocal learning relationships and a deepening participatory process, is very different to that required in more traditional practicum experiences. This role is a much more enhanced one and requires the prospective teachers to be pro-active learners, empathic and skilled communicators, emotionally strong and resilient. They need to be reflective practitioners who are committed to the development of collaborative learning cultures and to their dual roles in developing and supporting such cultures, toward a better future for the children.

\section{Recommendations}

While it is relatively easy to develop a list of laudable recommendations to support collaboration, the real challenge is in developing and carrying out an implementation plan. Two arenas should be considered: teacher education programs and schools.

Teacher education programmes should be encouraged to both teach and model collaborative practices. For this to occur, several changes are necessary. First of all it is necessary to extend class time on practicum to include 'a lab period' for 
additional collaborative discussion, reflection and work. Furthermore, thoughtful integrated courses of study must be created based on the collaboration of trainees, practitioners, and their tutors. Finally, it is necessary to develop trainee interdependence early in their preparation in order to combat the all too common sense of teacher isolation and foster the development of graduates who as professionals actively question, create, and implement policy.

On the basis of this study's outcomes further research is needed to build partnerships with selected schools and classroom teachers for continuing involvement in Early Childhood Collaborative Practicum, with the view to structure professional development for classroom teachers, to assist in familiarization of the practicum's requirements and investigate what specialized strategies can be offered to support those trainees who experience personal problems.

\section{References}

Barry, K., \& King, L. (2002). BeginningTeaching and Beyond, (3rd ed.). Tuggerah, NSW: Social Science Press.

Beck, C., \& Kosnik, C. (2002). Components of a Good Practicum Placement: Student Teacher Perceptions. Teacher Education Quarterly, 29(2), 81-98.

Britton, L. R., \& Anderson, K. A. (2010). Peer Coaching and Pre-service Teachers: Examining an Underutilized Concept. Teaching and Teacher Education, 26(2), 306-314.

Brock, B., \& Grady, M. (1998). Beginning Teacher Induction Programs: The Role of the Principal. Clearing House, 71(3), 79-83.

Cameron, R. \&Wilson, S. (1993). The Practicum: Student Teacher Perceptions of Teacher Supervision Roles. South Pacific Journal of Teacher Education, 21(2), 155-168.

Cohen, L., Manion, L., \& Morrison, K. (2007). Research Methods in Education, (6th ed.). London: Routledge, Falmer.

Dewey, J. (1938). Experience and Education. New York: Macmillan.

European Trade Union Committee for Education (ETUCE) (2008). Teacher Education in Europe: An ETUCE Policy Paper. Brussels: ETUCE.

Freese, A. R. (2005). Innovation and Change in Teacher Education: An Inquiring, Reflective, Collaborative Approach. In Hoban, G. F., (Ed.), The Missing Links in Teacher Education Design: Developing A Multi-linked Conceptual Framework, Vol. 1, Springer, (pp117-133). The Netherlands: Dordrecht.

Glaser, B. G., \& Strauss, A. L. (1967). The Discovery of Grounded Theory: Strategies for Qualitative Research. New York, NY: Aldine de Gruyter.

Glesne, C. (2006). Becoming Qualitative Researchers: An Introduction. Boston: Allyn \& Bacon.

Goodfellow, J. (1995). A Matter of Professional Style: Implications for the Development of Purposeful Partnerships between Cooperating Teachers and Student Teachers. Paper Presented at the Peer Education Pan Europe (PEPE) Conference, 3-6 February, Broadbeach, QLD.

Gourgiotou, E. (2014). Transition and Continuity in Education. Thessaloniki: Disigma.

Graham, B. (2006). Conditions for Successful Field Experiences; Perceptions of Cooperating Teachers. Teaching Teacher Education, 22, $1118-1129$.

Grootenboer, P. (2006). The Impact of the School-Based Practicum on Pre-service Teachers' Affective Development in Mathematics. Mathematics Teacher Education and Development, 7, 18-32.

Grossman, P., Wineburg, S. \& Woolworth, S. (2001). Toward a Theory of Teacher Community. Teachers College Record, 103(6), 942-1012.

Hargreaves, A. (1998). The Emotional Practice of Teaching. Teaching and Teacher Education, 14(8), 835-854.

Hoover, L. A. (1994). Reflective Writing as a Window on Pre-service Teachers' Thought Processes. Teaching and Teacher Education, 10(1), 83-93.

Hsu, S. (2005). Help Seeking Behaviour of Student Teachers. Educational Research, 47(3), 307-318.

Huling-Austin, L. (1992). Research on Learning to Teach. Journal of Teacher Education, 43(3), 173-180.

Joyce, B. R., Weil, M., \& Showers, B. (1992). Models of teaching, (4th ed.). Boston: Allyn and Bacon.

Kwo, O. W. Y. (2001). Peer Support for Professional Learning: Rewards and Challenges. In Kember, D., Candlin, S. and Yan, L. (Eds.), Further Case Studies of Improving Teaching and Learning from Action Learning Project (pp. 307-320). Hong Kong: The Hong Kong Polytechnic University.

Le Cornu, R., \& Ewing, R. (2008). Reconceptualising Professional Experiences in Pre-service Teacher Education Reconstructing the Past to Embrace the Future. Teaching and Teacher Education, 24(7), 799-1812.

Leinhardt, G., \& Steele, M. (2005). Seeing the Complexity of Standing to the Side: Instructional Dialogues. Cognition and Instruction, 23(1), 87-163.

Lieberman, A., \& Pointer Mace, D. H. (2008). Teacher Learning: The Key to Educational Reform. Journal of Teacher Education, 59(3), 226-234.

Lincoln, Y. S., \& Guba, E. G. (1985). Naturalistic Inquiry. Beverly Hills, CA: Sage Publishing, Inc.

Little, J. W. (1982). Norms of Collegiality and Experimentation: Workplace Conditions of School Success. American Educational Research Journal, 19(3), 325-340.

Loughran, J. (1996). Developing Reflective Practice: Learning about Teaching and Learning through Modelling. London: Falmer Press. 
McAninch, A. C. (2000). Continuity and Purpose in the Design of Meaningful Project Work. Early Childhood Research \& Practice (ECRD), 2(1), 1-10. Accessed online http:/ecrp.uine.edu/v2n1/mcaninch.html.

McLean, S. V. (1991). The Human Encounter: Teachers and Children Living Together in Preschools. London: Falmer Press.

Neubert, G. \& Binko, J. B. (1992). Inductive Reasoning in the Secondary Classroom. Washington, DC: National Education Association.

Nie, Y., \& Lau, S. (2009). Complementary Roles of Care and Behavioural Control in Classroom Management: The Self-determination Theory Perspective. Contemporary Educational Psychology, 34, 185-194.

Nokes, J. D., Bullough, R. V., Egan, W. M., Birrell, J. R., \& Hansen, J. M. (2008). The Paired-placement of Student Teachers: An Alternative to Traditional Placements in Secondary Schools. Teaching and Teacher Education, 24, 2168-2177.

Numrich, C. (1996). On Becoming a Language Teacher: Insights from Diary Studies. TESOL Quarterly, 30(1), 131-53.

Ong'ondo, C. O., \& Jwan, J. O. (2009). Research on Student Teacher Learning, Collaboration and Supervision during the Practicum: A Literature Review. Educational Research and Reviews, 4(11), 515-524.

Paton, M. (2002). Qualitative Research \& Evaluation Methods (3rd ed.). Thousand Oaks, CA: Washington, DC.

Reiman, A. J., \& Johnson, L. (2003). Promoting Teacher Professional Judgment. Journal of Research in Education, $13(1)$, $4-14$.

Simonsen, B., Fairbanks, S., Briesch, A., Myers, D., \& Sugai, G. (2008). Evidence-Based Practices in Classroom Management: Considerations for Research to Practice. Education and Treatment of Children, 31, 351-380.

Stein, L. (2010). Lead Students-Don't Just Manage Them. Kappan, 91(4), 82-86.

Subramanian, M. (1997). Journal Writing as a Tool for Teacher Trainees' Reflection on Teaching. Unpublished Master's Thesis. University of Massey, NZ,available at: http://www.mpbl.edu.my/mpbl103/research/2001/2001man0.pdf (accessed 12 September 2012).

Surbeck, E., Han, E. P., \& Moyer, J. E. (1991). Assessing Reflective Responses in Journals. Educational Leadership, 48(6), $25-27$.

Turney, C., Eltis, K. Towler, J., \& Wright, R. (1985). A New Basis for Teacher Education: The Practicum Curriculum. Sydney: Sydmac Academic Press,

Van Manen, M. (1977). Linking Ways of Knowing and Ways of Being Practical. Curriculum Inquiry, 6, 205-228.

Vidmar, D. (2006). Reflective Peer Coaching: Crafting Collaborative Self-assessment in Teaching. Research Strategies, $20,135-148$.

Walsh, K., \& Elmslie, L. (2005). Practicum Pairs: An Alternative for First Field Experience in Early Childhood Teacher Education. Asia Pacific Journal of Teacher Education, 33(1), 5-21.

Wilson, G., \& I'Anson, J. (2006). Reframing the Practicum: Constructing Performative Space in Initial Teacher Education. Teaching and Teacher Education, 22(3), 353-361.

Wynn, M. J., \& Kromrey (1999). Paired Peer Placements with Peer Coaching in Early Field Experiences: Results of a Four Year Study. Teacher Education Quarterly, 26, 21-38.

Zeichner, K. (1990). Changing Directions in the Practicum: Looking Ahead to the 1990s. Journal of Education for Teaching, 16(2), 105-125. 